\title{
Industrial experiences in the evaluation of various flotation reagent schemes for the recovery of gold
}

\author{
R.R. Klimpel
}

\begin{abstract}
This paper is a summary of the author's industrial experiences on the selection and optimization of flotation reagent schemes for the recovery of gold species. The trends given are a composite of data and experiences gained on 24 different gold ores from around the globe. The primary emphasis is on the benefits of matching the associated gold mineralogy to a reagent scheme most appropriate for that mineralogy. Two general categories are discussed: the flotation of free or native gold species and the flotation of gold associated with a variety of sulfide minerals. Important plant operating factors influencing each of these two categories are presented with supporting examples. Carefully matching reagent chemistry and appropriate operating conditions to any given gold-bearing ore will not only lower the total reagent cost but, more importantly, can lead to measurable increases in gold recovery.
\end{abstract}

\section{Key words: Flotation, Reagents, Gold recovery}

\section{Introduction}

The industrial processing of ores containing precious metals such as gold is generally very mining-site specific, e.g., McQuiston and Shoemaker (1985), vanZyl et al. (1988), Fuerstenau and Hendrix (1990) and Hausen et al. (1990). The variety of various mineral-processing techniques employed is extensive and includes size reduction, size classification, gravity separation, roasting, cyanidation, chemical and/or bacterial leaching, ion exchange (including solvent extraction) and froth flotation. The average gold concentration in the earth's crust is very low and has been estimated by various sources to be between 2 and $5 \mathrm{ppb}$.

For a specific deposit to be considered an economic source of gold, generally a concentration of near $1 \mathrm{ppm}(1 \mathrm{~g} / \mathrm{t}$ or $0.029 \mathrm{oz} / \mathrm{st}$ ) or more is required. From a mineralogical viewpoint, gold often occurs in its native or free form. However, it can also occur as gold compounds of telluride, antimony and selenium, which are contained within sulfide minerals such as pyrite, arsenopyrite and pyrrhotite or, to a lesser extent, it can be contained within silicate, oxide and carbonate minerals. In many locations, alloying of gold with silver is found.
The optimal processing method for recovering gold is determined by many factors. These include:

- the mineralogies of the gold-bearing and gangue minerals,

- the type of liberation profile of the gold-bearing minerals upon size reduction and

- the particle size of the gold itself.

Free or native gold particles can vary in size from large nuggets to very finely disseminated gold associated in a complex-sulfide mineral matrix.

Typically, free gold particles of several hundred microns or larger are efficiently recovered by one or more of a number of gravity-based techniques. These techniques are successful because of the large specific gravity differential between gold (15 to 19.3) and typical gangue minerals (2.7 to 5). When gold is associated with a sulfide (usually pyrite) matrix, historically, most industrial plants involving size reduction and subsequent liberation have operated in a size range of $50 \%$ to $80 \%$ less than $75 \mu \mathrm{m}$. Grinding finer than this has normally been uneconomical, unless the ore has a high gold content in the feed ore.

Except for the notable exception of the finely disseminated nature of the gold ores of the Carlin Trend in Nevada, typically, the processing scheme includes a flotation concentration step before or after a cyanidation step. The use of cyanide as a gold-leaching process is generally inhibited by the presence of species such as pyrrhotite, arsenopyrite, stibnite, marcasite, active carbonaceous material and some copper minerals such as chalcocite and malachite. The cyanide-leaching process is generally inhibited by the above materials, either due to the consumption of oxygen, which slows the rate of gold cyanidation and/or the consumption of large quantities of cyanide, resulting in poor process economics. In the case of active carbonaceous materials being present, such materials can behave like activated carbon and adsorb gold from cyanide solutions. For ores that are refractory in nature, roasting and bacterial/pressure leaching is used to liberate gold prior to cyanidation.

Froth flotation in gold processing has been used for many years on a broad scale in many areas of the world, e.g.,

R.R. Klimpel, deceased, was president of RK Associates LLC, Midland, MI. Preprint number 98-083, presented at the SME Annual Meeting, March 9-11, 1998, Orlando, FL. Paper accepted for publication September 1998. 


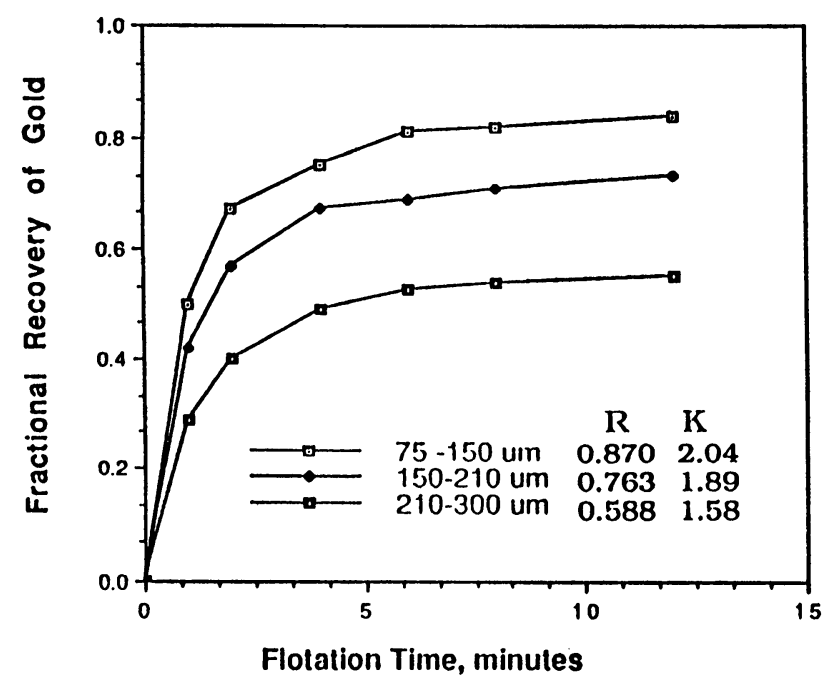

Figure 1 - The time-recovery profiles of free gold in a batch laboratory flotation cell without collector and with PGME frother (molecular weight 200) added at $20 \mathrm{~g} / \mathrm{t}$.

Klimpel and Isherwood (1993) and O'Connor and Dunne (1994), with South Africa being a very large-scale user of gold-flotation technology for many years.

The purpose of this paper is to summarize this author's experiences over the last 20 years in the selection and/or optimization of reagent schemes with 24 different gold ores. This article will not discuss reagent chemistry mechanisms, but rather it will concentrate on application methodologies. There are a number of useful review articles available on the general fundamentals of sulfide collector flotation (Fuerstenau et al., 1985; Aplan and Chander, 1988; Fuerstenau, 1989). These articles provide a theoretical background of the reagent mechanisms on the surfaces of mineral.

In addition, some useful plant-oriented references on general sulfide applications and trends include Lynch et al. (1981), Klimpel (1989, 1995), Crozier (1992) and Malhotra (1993). Some of the material presented in this article is based on the background information contained in the above references. No attempt was made to reference all of the literature articles available on gold flotation, but rather the emphasis will be on presenting an integrated picture of some overall plant reagent-use trends.

The incentives for using flotation as a processing step include its high throughput at relatively low capital and operating costs, it's high mineral specificity and its high operating flexibility, e.g., Klimpel (1995). The ever increasing availability of effective collectors and frothers for gold flotation along with improved application methodology are also helping to increase the use of froth flotation as an integral step in the overall gold-processing arena.

From the viewpoint of gold mineralogy interacting with reagent chemistry, it is useful to characterize the various possible reagent philosophies into two general categories: the flotation of free or native gold species and the recovery of gold associated with a variety of sulfide minerals. These two categories are discussed in detail with illustrating examples, presenting important factors that appear to be somewhat general in application. All of the experimental examples presented in this paper were previously unpublished and, in most cases, represent a substantial experimental effort to arrive at the data.

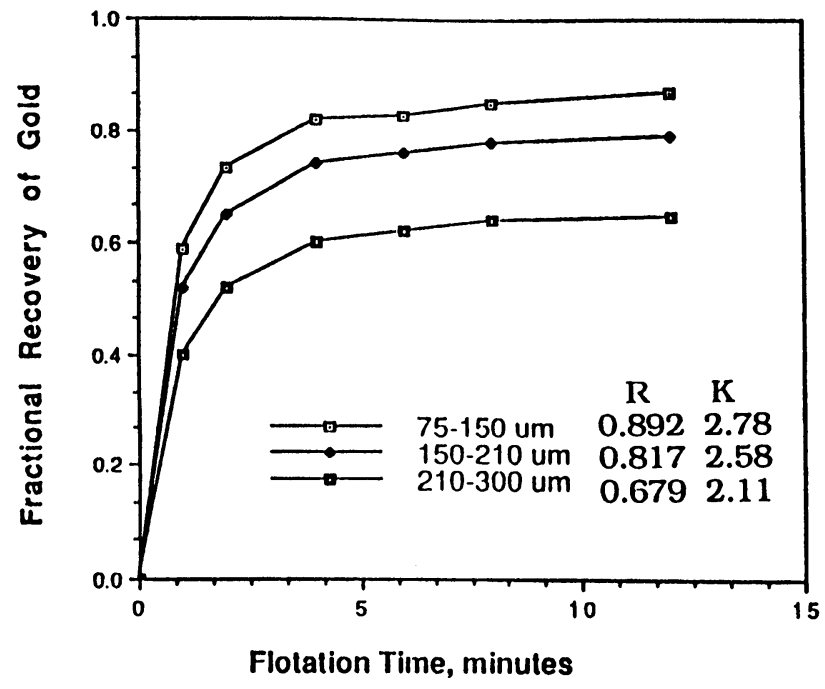

Figure 2 - The time-recovery profiles of free gold in a batch laboratory flotation cell with $10 \mathrm{~g} / \mathrm{t}$ of a thionocarbamate collector added to the grind and PGME frother (molecular weight 200) added at $20 \mathrm{~g} / \mathrm{t}$.

\section{Flotation of ores containing native gold species}

The surfaces of native or free gold-containing particles are normally hydrophobic and, if the surfaces of such particles are relatively free of contaminants, they will have a tendency to float without the addition of a collector. The major sources of contamination on free gold particles are processing chemicals and small-particle slime coatings. Gold tellurides also have a strong natural flotation tendency and will, for the purpose of this article, be included in this natural-flotation discussion.

The trends in the area of free gold that will be addressed in this section include:

- the impact of gold particle size on the recovery and rate of flotation,

- the need to choose collector type carefully to minimize collector dosage and to be at or near natural ore $\mathrm{pH}$ conditions,

- the importance of a balanced frother selection,

- some special operating factors and

- the processing of carbonaceous gold ores.

Particle size effects. As mentioned earlier, natural or collectorless flotation of native or free gold is generally possible, at least to a degree, with many gold-containing ores. The first factor in such flotation studies is the quantification of what the limitations are of particle size on the flotation process. Some unique studies have been conducted by this author at a number of plants. Figures 1 and 2 show the results of a kinetic study done on a free gold ore from Africa. The laboratory work was done using a large 3-L (0.8-gal) batch cell. All of the data taken was at the natural ore $\mathrm{pH}$ of $7.3-$ no $\mathrm{pH}$ regulators of any kind were used. Figure 1 summarizes the time-recovery data with no collector as a function of goldparticle size range, and Fig. 2 summarizes the same kind of data with $10 \mathrm{~g} / \mathrm{t}(0.02 \mathrm{lb} / \mathrm{st})$ of ethyl isopropyl thionocarbamate added to the grind. The frother used in this study was a polypropylene glycol methyl ether (PGME) of 200 molecular weight. The nominal grind size for the data of both figures was $52.5 \%<75 \mu \mathrm{m}$, which is deliberately coarse, so as to have a broad range of gold particle sizes in the flotation feed. 
The batch time recovery data of Figs. 1 and 2 was curve fitted to a modified first-order rate model that was frequently used by this author and others in kinetic studies (Klimpel, 1980, 1989, 1995; Dowling et al., 1985). The model is given by the equation

$$
r_{i}=R\left[1-\left(1 /\left(K t_{i}\right)\right)\left(1-\exp \left(-K t_{i}\right)\right)\right]
$$

where

$r_{i}$ and $t_{i}$ are paired sets of experimental cumulative recovery and cumulative time data, respectively;

$R$ is the curve-fitting parameter equal to the equilibrium recovery at long flotation time; and

$K$ is the curve-fitting parameter equal to a modified firstorder rate constant having units of time ${ }^{-1}$.

Thus, one complete time-recovery profile can be described by one set of $R$ and $K$ values, each with associated error limits. Comparing different time-recovery profiles generated under different sets of experimental conditions becomes a simpler problem of statistically comparing sets of $R$ and $K$ values. It usually is quite easy to see trends in the $R$ and $K$ values with organized experimental test programs. In the test work of Figs. 1 and 2, the approximate 95\% confidence limits on $K$ are \pm 0.26 and for $R$ are \pm 0.017 . The least-squares estimate of the $R$ and $K$ values for each profile is also given in the figures.

Inspection of Figs. 1 and 2 show a number of particle-size trends that are common to both gold flotation and sulfide mineral flotation, such as with chalcopyrite and molybdenite. To begin with, smaller gold particles float much faster than larger particles and also give higher equilibrium recoveries. This is true whether one has a collector present or not. The role of any collector with naturally floating minerals such as the free gold in Fig. 2 is to speed up the rate of recovery of all particle sizes with the relative impact being greatest on the coarser particles. Also, the presence of the collector helps to increase the equilibrium recoveries achievable, with the greatest impact again being on the coarsest particles.

The recovery of native gold particles below $150 \mu \mathrm{m}$ in many plants is often surprisingly good whether a collector is used or not.

Choice of collector type and dosage. The second major factor in the flotation of native or free gold is the choice of collector type and dosage. In this regard, it has consistently been this author's experience that, with inherently naturally floating minerals, the most effective collectors are those that are uncharged and water insoluble. These hydrophobic collectors operate best when used at or near the natural $\mathrm{pH}$ of the slurry, e.g. Klimpel (1995, 1997b). Typical uncharged and water-insoluble collectors useful in such flotations include:

- thionocarbamates $\left(\mathrm{R}^{\prime} \mathrm{HN}-(\mathrm{C}=\mathrm{S})-\mathrm{OR}^{\prime \prime}\right)$,

- xanthogen formates ( $\left.\mathrm{R}^{\prime} \mathrm{O}-(\mathrm{C}=\mathrm{S})-\mathrm{S}-(\mathrm{C}=\mathrm{S})-\mathrm{OR}^{\prime \prime}\right)$,

- mercaptans (RSH) and

- dialkyl sulfides ( $\left.\mathrm{R}^{\prime}-\mathrm{S}-\mathrm{R}^{\prime \prime}\right)$.

In contrast to this insoluble class are charged watersoluble collectors such as xanthates $\left(\mathrm{RO}-(\mathrm{C}=\mathrm{S})-\mathrm{S}^{-} \mathrm{M}^{+}\right)$and dithiophosphates $\left((\mathrm{RO})_{2}-(\mathrm{P}=\mathrm{S})^{-} \mathrm{S}^{+} \mathrm{M}^{+}\right)$. The reason for the natural $\mathrm{pH}$ is that $\mathrm{Ca}^{++}$is generally a native or free gold depressant, and, as will be shown below, the presence of lime slows down the flotation kinetics of gold species. Thus, if alkaline $\mathrm{pH}$ adjustment is necessary, it should be achieved with caustic $(\mathrm{NaOH})$, soda ash $(\mathrm{KOH})$, etc., and, generally, for acidic $\mathrm{pH}$ adjustment, sulfuric acid $\left(\mathrm{H}_{2} \mathrm{SO}_{4}\right)$ is normally used, although the use of hydrochloric acid $(\mathrm{HCl})$ can be beneficial.

There are a number of reasons why insoluble collectors are preferable for the recovery of naturally (collectorless) floating species. The first is that the use of water-soluble (hence hydrophilic) collectors such as xanthates and dithiophosphates definitely slows the rate of flotation of naturally floating minerals, including native gold. As will be shown in many different ways in this paper, gold flotation, under even the best of conditions, is inherently a slow rate process compared to other naturally floating minerals, such as chalcopyrite, and compared to other minerals requiring strong collector action, such as chalcocite and sphalerite. Thus, any condition that slows down the gold-recovery process needs to be avoided if at all possible.

The second reason is that much higher dosages of watersoluble collectors are required for equivalent optimal equilibrium recoveries than are required for water-insoluble collectors. Even with the water-soluble xanthate species, for example, only the larger carbon content $\mathrm{R}$ groups, such as amyl and butyl, appear to be effective as gold collectors at any dosage. Ethyl and propyl $\mathrm{R}$ groups in xanthates are very seldom considered for gold notation. The third reason is that naturally floatable minerals have a tendency to be naturally selective over many gangue minerals, including pyrite. The use of an uncharged water-insoluble collector helps to maintain this inherent selectivity whereas using a charged watersoluble collector rather quickly destroys this selectivity. Once this natural selectivity is destroyed, the plant is often then forced into using depressants such as cyanide, pyrite depressants of various types, $\mathrm{pH}$ regulators for mineral surface modification, etc.

Figure 3 shows the trends of $R$ and $K$ parameters as measured on another native gold ore from the Pacific Rim. Six different collector conditions, including collectorless flotation, were measured at a natural ore $\mathrm{pH}$ of 7.3. This ore has primarily free gold species, a very small amount of gold associated with pyrite and $5.6 \%$ (by weight) of the ore is pyrite. The trends shown in this figure are very typical of a large number of plant ores that this author has worked with. Also, all of the reasons given above for the desirability of using the above uncharged water-insoluble collectors for the optimal recovery of naturally floatable ores are verified in graphical form in Fig. 3.

To begin with, it can be seen that both the collectorlessflotation equilibrium recovery and the associated flotation rate are higher than with small dosages $(12.5 \mathrm{~g} / \mathrm{t})$ of xanthate and dithiophosphate. The equivalent small dosage of $12.5 \mathrm{~g} / \mathrm{t}$ of the thionocarbamate (ethyl isopropyl) and the dialkyl sulfide clearly gives superior recoveries and rates. It is only at high dosages of amyl xanthate, i.e., $100 \mathrm{~g} / \mathrm{t}$ or more, that the equilibrium recovery $R$ for the xanthate equals that of the $R$ for the insoluble collectors at $12.5 \mathrm{~g} / \mathrm{t}$. The collector RKS-100 also shown in Fig. 3 is an experimental uncharged collector being developed by RK Associates specifically to enhance the recovery of naturally floating minerals.

The di-isobutyl dithiophosphate results are similar to those of the xanthate, except that a low equilibrium gold recovery is achieved regardless of the dosage used. Whatever gold recovery the insoluble collectors are going to achieve is basically achieved by 25 to $50 \mathrm{~g} / \mathrm{t}$, and higher dosages of these specific collectors really accomplishes little. The higher dosage of charged collectors also has another characteristic of poor pyrite selectivity, which will be shown below. 

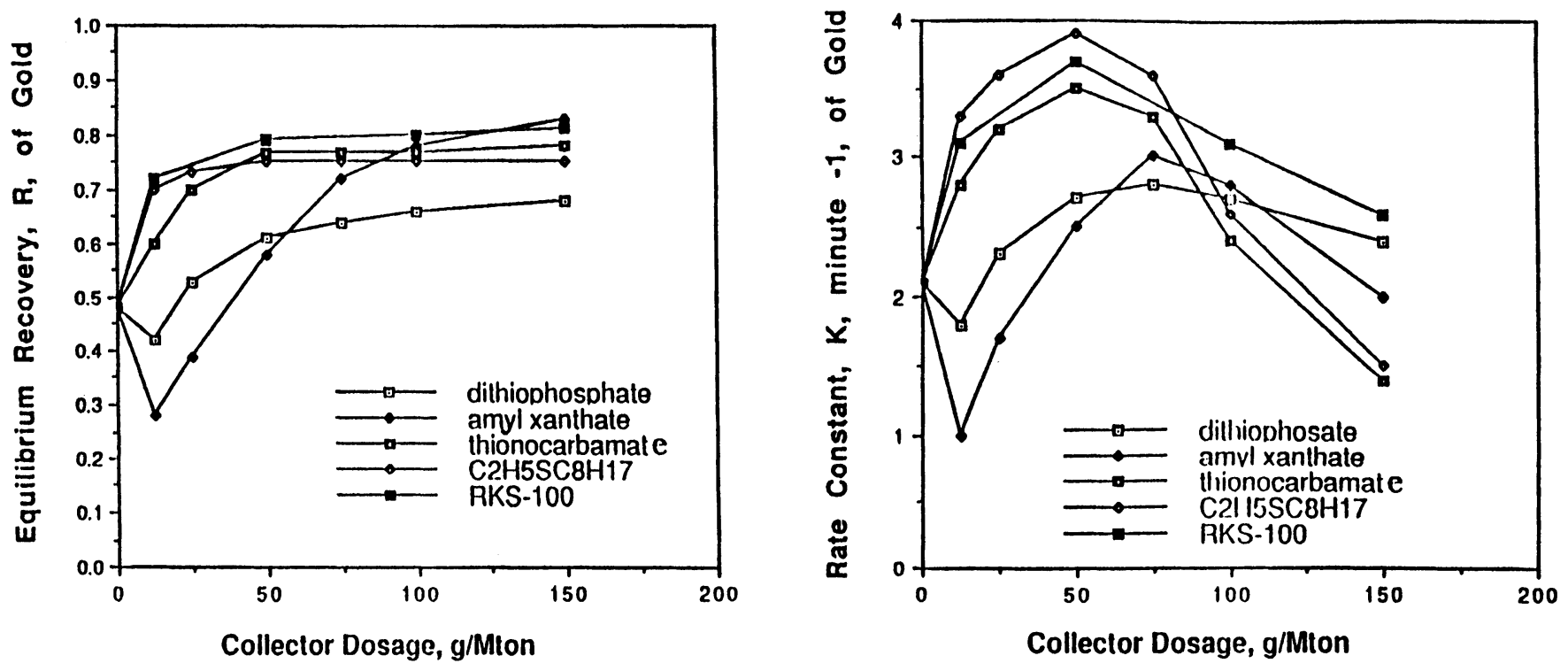

Figure 3-The trends in $\mathrm{R}$ and K parameters resulting from curve fitting experimental time-recovery profiles for free gold using various collectors at varying dosage levels using PGME frother (molecular weight 200) at $15 \mathrm{~g} / \mathrm{t}$.

The fact that the rate of flotation goes through a maximum with collector dosage has been well documented on many mineral systems by this author (e.g., Klimpel, 1989, 1995, 1997a). The reason for this is the nature of surfactant (collector) adsorption on various particle sizes (i.e., adsorption occurs as a function of surface area that is dominated by the smaller particle sizes).

This situation leads to coarser particles being undercollected in a flotation feed mixture, while the finer particles are being overcollected. Hence, with increasing collector dosage, there is a tendency for the rate of the coarser particles to increase while, at the same time, the rate of flotation of the finer particles is decreasing. This phenomena is called the $\mathrm{R} / \mathrm{K}$ trade-off, and some very useful plant data is available showing quantitatively the changes in particle size flotation rate with changing collector dosage (Klimpel, 1995,1997a).

Figure 3 also shows a trend that has been often noticed by this author with naturally floating minerals. That is, the location of the rate maximum occurs at much smaller dosages of uncharged water-insoluble collectors than with charged water-soluble collectors. The data of Fig. 3 illustrates an extremely important reagent use guideline for inherently naturally floating minerals, including free gold, it is generally optimal to use small levels of uncharged water-insoluble collectors at near natural ore slurry $\mathrm{pH}$ levels. To do other than this is taking away much of the inherent processing advantages offered by naturally floating minerals, as well as unduly adding to the total reagent cost.

It is interesting to note in the flotation of naturally floating minerals, that even a small amount of xanthate or organic degradation products in the plant flotation water will cause significant changes in the selectivity of naturally floating minerals, especially against pyrite and pyrrhotite (Klimpel, 1997b). For example, in this reference, some data is presented where water purification was conducted to remove residual xanthate from the recycle water in a plant that had been using xanthates for a long time. When this water purification was done, and uncharged water-insoluble collectors were then used, there were dramatic effects measured with regard to selectivity of a chalcopyrite ore over pyrite. It is fully anticipated that exactly the same results would be applicable to the flotation of natural or free gold-containing ores.

Experience has clearly shown that free gold particles can be recovered very selectively, especially against pyrite, by keeping the gold particle surfaces as clean of organic species as possible and by removing any adhering slime particles. Thus, for improving selectivity, this clearly implies the use of little or no $\mathrm{pH}$ regulators, only small dosages of uncharged collectors $(<10 \mathrm{~g} / \mathrm{t})$, only enough of a particle-size balanced frother to stabilize the froth phase and possibly a small amount of dispersant, which will be discussed below.

The sometimes observed tendency to treat gold ores containing free or native gold as though the gold was associated in a massive or complex sulfide matrix, which implies high dosages of xanthates or dithiophosphates, high levels of lime, and possibly some activators and depressants, really adds an unnecessary reagent cost and operating complexity to a plant operation.

Even more importantly, the over reagentizing of native gold-containing ores can be negative on achieving high gold recovery and grade and also negative on downstream processes such as filtration. Some experiences on processing mixed gold ores that contain some free gold as well as gold associated with other sulfide mineral species will be discussed later in the article.

Thus, to complete the picture, Fig. 4 gives the pyrite recovery associated with the data of Fig. 3. As might be expected due to the natural ore $\mathrm{pH}$ of 7.3 , the pyrite selectivity gets dramatically worse with the xanthate, is intermediate in nature for the thionocarbamate and is best for the dialkyl sulfide and the RKS-100. Figures 3 and 4 show the dilemma of using charged water-soluble collectors for the flotation of free gold at the natural $\mathrm{pH}$ range. If such collectors are not added at high enough dosages, both the rates of recovery and the desired equilibrium recoveries are not high enough to be economic. Yet, at high collector dosages of the charge collectors, the selectivity over other sulfide minerals such as pyrite becomes very poor. Raising the $\mathrm{pH}$ to overcome this selectivity problem then introduces a number of other problems such as gold depression, increased slime effects and slower flotation rates (to be shown in the section on gold associated with sulfide minerals). 


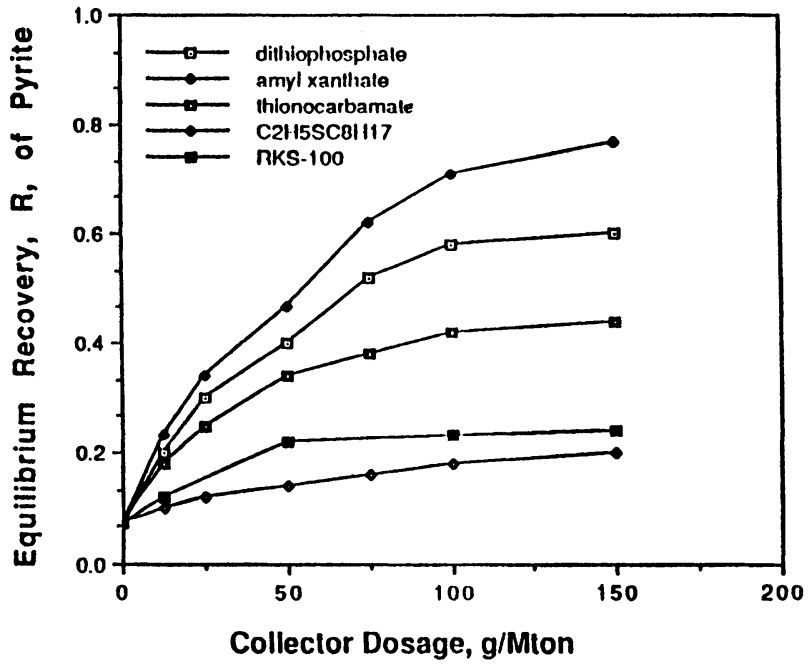

Figure 4 - The trend in pyrite recovery in the flotation of free gold using various collectors at varying dosage levels using PGME frother (molecular weight 200) at $15 \mathrm{~g} / \mathrm{t}$.

Frother selection. A number of useful plant-oriented references on frothers are available, e.g., Riggs (1986) and Klimpel and Isherwood (1991). The concept of blending frother components so as to maximize a plant's ability to effectively float a broad range of particle sizes has been well documented in the above references.

The general conclusions of this work in achieving particle size balanced frothers are:

- different frother components are most effective on certain particle sizes;

- to a first approximation, blending of appropriate largeand small-particle frother components, gives an additive effect of broadening out the total particle size range recoverable;

- many more types of chemical structures can be used as blending components than were previously thought based on using a given component just as a stand alone frother; and

- it is possible to effectively blend frother components not only for particle size but for rate of flotation effects as well.

One major extra observation should be mentioned on frothers. This is that it has been this author's experience in gold flotation that pine oil, glycols $\left(\mathrm{H}-\left(\mathrm{OC}_{3} \mathrm{H}_{6}\right)_{n}-\mathrm{OH}\right)$, polypropylene glycol and methyl ethers $\left(\mathrm{CH}_{3}-\left(\mathrm{OC}_{3} \mathrm{H}_{6}\right)_{n}-\mathrm{OH}\right)$ are usually much more effective frothers from a recovery viewpoint than alcohol-based frothers $(\mathrm{R}-\mathrm{OH})$. Froth formation with native gold flotation can sometimes be a problem, so that stronger and more stable frothing chemicals are required. It is of particular interest to note that tripolypropylene glycol methyl ether $\left(\mathrm{CH}_{3}-\left(\mathrm{OC}_{3} \mathrm{H}_{6}\right)_{3}-\mathrm{OH}\right), 200$ molecular weight, has very often shown unusually high gold recoveries relative to other frothers.

Some other important factors. There is a host of other factors that could be discussed relative to their impact on the effectiveness of free gold flotation. One of the most consistent trends experienced over the years in gold flotation has been the need for carrying out flotations on grouted ore pulps having relatively high percent solid loadings (by weight).

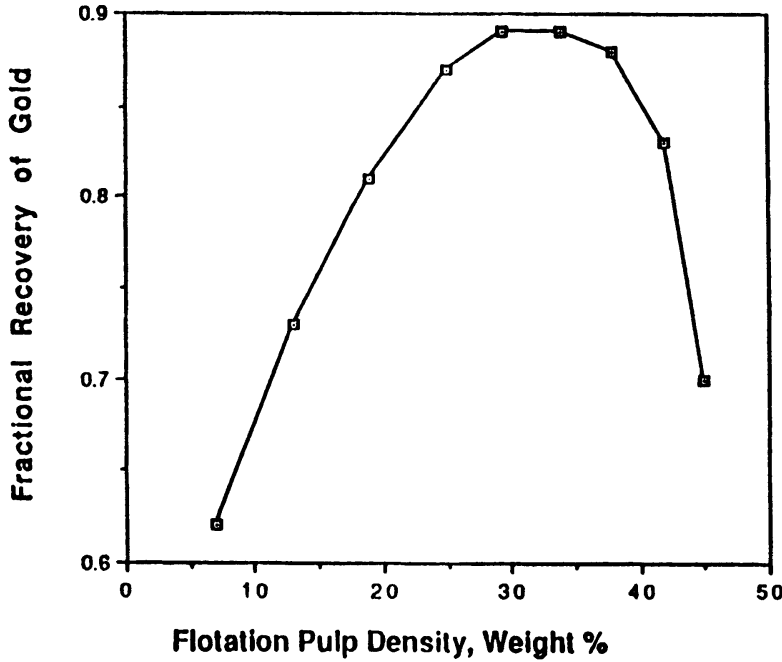

Figure 5 - Gold recovery as a function of pulp density in a rougher bank of eight equal-size mechanical cells using dialkyl thionocarbamate collector at $45 \mathrm{~g} / \mathrm{t}$ and $P G M E$ frother at $15 \mathrm{~g} / \mathrm{t}$.

The data of Fig. 5 from South Africa illustrates this point quite well. The ore being treated has both free gold and gold associated with pyrite. Quite simply stated, if the pulp density is not maintained at $30 \%$ or higher (by weight), it is very difficult to keep the coarser free gold in the froth phase.

Copper sulfate is often used as an activator for promoting free gold flotation. Often in plants using $\mathrm{CuSO}_{4}$, it has been this author's experience that this activation has not been possible to verify quantitatively. Because of the difficulty of sometimes maintaining an effective froth phase, the frother dosage can be too high and the copper sulfate appears to be more of a froth modifier than a true activator.

Generally, the presence of lime can be shown to be negative on the recovery of free gold. This is part of the trap that a plant operator can fall into using water-soluble charged collectors to float native gold. Lime is often necessary to maintain selectivity with such collectors, but, then, high collector dosages are required to maintain recovery and overcome any $\mathrm{Ca}^{++}$effect, and so on.

Temperature also can be an important variable and clearly cold pulp temperatures below $25^{\circ} \mathrm{C}$ can have a negative impact on flotation kinetics due to the changing viscosity effects of temperature on mineral pulps. Thus, in some plants in the cooler months of the year, some type of heat exchange system has been installed so as to maintain flotation kinetics by preheating process water, so that the resulting flotation feed pulps are roughly at room temperature. On the other hand, temperatures above $50^{\circ} \mathrm{C}$ can also be negative on flotation, presumably due to desorption of collector species from the mineral surface or some other surface related phenomena.

The recovery of free gold and/or gold associated with other sulfide minerals is inherently a slow process relative to other types of sulfide mineral flotation. Thus, avoiding any operating condition that inadvertently slows down the rate of flotation, including reagent overdosing, should be avoided if at all possible. In gold flotation, probably the best flotation equipment design approach is to put in as much equipment volume and residence time as is economically warranted by the ore value itself. Having lots of rougher and scavenger capacity has saved more than one gold operation in an economic sense. 
Naturally floating minerals are also not very sensitive to water chemistry factors, including hardness and high ionic strength, e.g. Klimpel (1997b). Therefore, flotation circuits for processing primarily naturally floating minerals can operate effectively on some fairly marginal processing water, including seawater. The ability to use seawater can have an enormous impact of flotation economics with little, if any, deterioration of recoveries and grades.

Carbonaceous gold ores. Some plants have to deal with the presence of surface-active carbon materials in the ore. It is not uncommon for the carbonaceous material to contain significant levels of gold. In other situations, the carbonaceous material is relatively devoid of gold but has the tendency to adsorb large amounts of collectors, thereby, increasing significantly the total reagent cost. In either case, it is generally best to initially float the carbonaceous material, because it has high natural hydrophobicity and tends to float naturally. Thus, the flotation of carbonaceous material is really nothing more than a special case of natural gold flotation, as has already been addressed in the article.

It is sometimes possible to float this type of material by simply adding a frother at natural ore $\mathrm{pH}$ and carrying out the flotation. However, the addition of kerosene or fuel oil can help promote both the rate and final recovery of the carbonaceous material. Care has to be taken to not add too much hydrocarbon, as it is easy to end up with a real mess from an operating viewpoint. Also, the use of small amounts of uncharged water-insoluble collectors is also effective in such flotations.

If there is no gold present in the prefloated material, then, such material can be simply removed from the flotation circuit. A major problem is the presence of carbonaceous material that contains gold in addition to gold associated with sulfide minerals in the ore.

Sometimes it is necessary to treat the gold in the carbonaceous fraction by a separate circuit or process, thus removing such material from the flotation circuit that is treating the remainder of the ore. Whether or not the carbonaceous concentrate and the remaining gold-containing concentrate can be cleaned in the same cleaner circuit simultaneously is very dependent on the ore and plant in question. The major trend here is that the removal of carbonaceous material is most easily done initially, with no $\mathrm{pH}$ adjustment and either a little hydrocarbon or a little water-insoluble collector.

\section{Flotation of gold associated with sulfide minerals}

There are many examples of gold ores that are associated with a variety of sulfide minerals. Five specific mineralogy systems will be addressed in this section:

- gold associated with naturally floatable copper ores, such as chalcopyrite and bornite;

- gold associated with pyrite, pyrrhotite and arsenopyrite;

- gold associated with $\mathrm{Cu} / \mathrm{Pb} / \mathrm{Ag} / \mathrm{Zn}$ sulfide minerals;

- mixed gold-ore systems in which some of the gold occurs in native form and some is associated with sulfide minerals; and

- gold ores that have high slime characteristics.

To start, it is important to note that some of the factors discussed in the free-gold section also apply to the recovery of gold associated with sulfide minerals. For example, the comments on the selection of frothers, the influence of high pulp densities in flotation, the impact of temperature, the $\mathrm{R} / \mathrm{K}$ trade-off with increasing collector dosage and the importance of maintaining flotation kinetics apply equally well to the mineral systems to be discussed in this section. The factors that are quite different in this section are the impact of $\mathrm{pH}$, the optimal choice of collector types and dosages and the need for activators and depressants.

Gold associated with chalcopyrite and bornite. The author has worked on a number of ores where much of the gold value in the ore has been associated with naturally floatable species such as chalcopyrite and bornite. The optimal reagent philosophy for such ores has turned out, not surprisingly, to be almost exactly the same as that discussed in the free-gold section of this paper.

Optimal results are achieved at near natural ore $\mathrm{pH}$ and using low levels of uncharged water-insoluble collectors. In a few cases, no collector at all was possible, but always the presence of even $5 \mathrm{~g} / \mathrm{t}$ of collector helps to stabilize the flotation somewhat, to maintain a consistent level of recovery and to increase the rate.

Sulfide minerals such as chalcopyrite, molybdenite and bornite have strong natural (collectorless) flotation tendencies due to their electrochemical response following fresh surface-area creation by grinding. The fresh sulfide-mineral surfaces are quite reactive, and, in the process of taking up oxygen, a window of sulfur-rich surface species is formed. This sulfur intensive and highly hydrophobic surface coating acts as though a collector was adsorbed, e.g., Woods (1988).

Recently, some new collector reagent ideas have been suggested that deliberately take advantage of this electrochemical transformation that occurs on certain sulfide minerals. This is the basis for the initial development of the R'-S-R' chemistry (Klimpel, 1995), and the proprietary product family that includes the RKS-100 product illustrated earlier. When gold is associated with such minerals, the best thing is to let the associated gold float without any undue or negative effects of excessive collector dosage or elevated $\mathrm{pH}$.

Figures 6 and 7 give a typical example of such a chalcopyrite ore having associated gold from North America. The copper recovery is shown in Fig. 6, and the gold recovery is shown in Fig. 7. The $\mathrm{pH}$ is being controlled by lime addition. The dithiophosphate is a di-isobutyl form, and the thionocarbamate is the ethyl/isopropyl form. Both the copper and gold recovery maximum with the two uncharged waterinsoluble collectors occurs at the lower $\mathrm{pH}$ of 9.1 , compared to the recovery maximum of the two charged water-soluble collectors at a pH of 10.5. The maximum copper recovery possible with any of the collectors is more or less the same.

However, in the case of gold recovery, the maximum gold recovery with the charged water-soluble collectors does not match the maximum recovery of the uncharged collectors. This difference in gold recovery in such a system has been observed in several different ores of this general classification. The reason for this is simple and is due to a loss of flotation rate, which occurs when the charged collectors are used on naturally floating materials. A detailed example of this loss of rate when using charged collectors on naturally floatable minerals was shown in Fig. 3 above.

In the experiments leading to the recovery data shown in Figs. 6 and 7, there was a deliberate flotation time limit of 12 min placed on the recovery process. The rates of flotation of both the chalcopyrite and the associated gold with chalcopyrite become slower with the use of charged collectors. However, the starting flotation rate of the chalcopyrite with little 


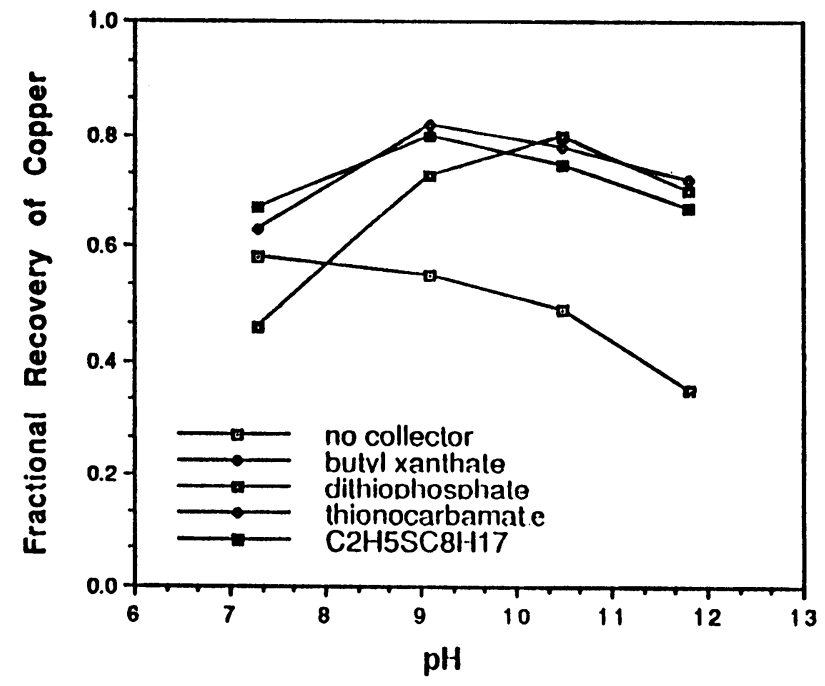

Figure 6 - Copper recoveries from chalcopyrite ore containing associated gold as a function of collector type using a blended alcohol and PGME frother at $15 \mathrm{~g} / \mathrm{t}$.

or no collector is sufficiently high in value that some decrease in rate does not dramatically affect the overall copper recovery due to the time limitation.

Unfortunately, in the case of the associated gold with chalcopyrite, the initial rate of flotation is slow enough that any decrease in rate due to the choice of collector will impact the observed recoveries in a set time limit. In this example, the time of flotation required to give equal gold recoveries with all of the different collectors is 18 to $20 \mathrm{~min}$. Again, this enforces the comment given earlier, that the choice of any operating factor, which unnecessarily slows down the rate of gold flotation, can and probably will give an adverse effect on gold recovery. Using charged water-soluble collectors at the higher dosages required to give acceptable gold recovery will almost always cause this fall-off in rate.

If a plant has very ample capacity, then this loss of rate is recoverable by the greater residence time. Of course, this excessive capacity is nice to have but is expensive and not possible in many existing plants. Also, the high $\mathrm{Ca}^{++}$loadings required for the charged water-soluble collectors are not helping the gold flotation rates and ultimate recoveries either.

Gold associated with pyrite, pyrrhotite and arsenopyrite. One of the more common classes of ores containing gold is when gold is associated with pyrite, pyrrhotite and arsenopyrite. This is the area of gold recovery that has probably received the most research and plant-optimization support, especially in light of the long history of South African industrial practice. From a reagent viewpoint, charged watersoluble collectors such as xanthates, dithiophosphates, some thiophosphate analogs, including phosphinates, and some recent adaptations of nitrogen-based collectors starting from either urea and/or amines, are the most successful reagents used, e.g., Klimpel (1994). Pyrite as it occurs in sulfide mineral systems requires a collector to float. There is a great deal of fundamental research currently going on in the flotation of pyrite with various chemical structures.

Experience has shown that in the acid pH range of 4 to 5 , almost all standard thio collectors are effective as pyrite collectors. Xanthates are not stable at these acid pH levels, e.g., Harris (1988), so that they are used in pyrite flotations only at alkaline $\mathrm{pH}$ levels. Collectors such as mercapto-

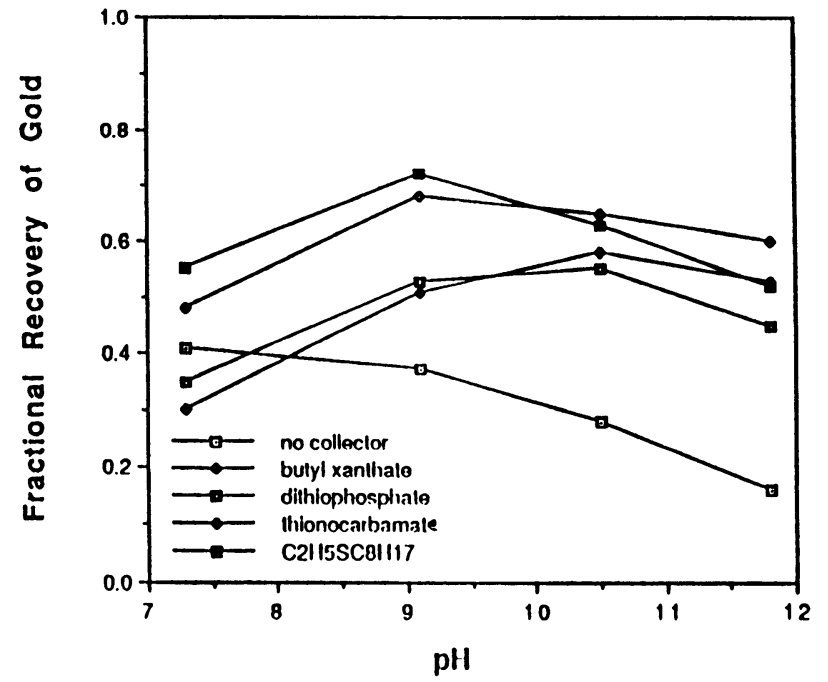

Figure 7 - Gold recoveries from a chalcopyrite ore containing associated gold as a function of collector type using a blended alcohol and PGME frother at $15 \mathrm{~g} / \mathrm{t}$.

benzothiazole, dithiophosphates, monothiophosphates, thionocarbamates and dialkly sulfides all have the capability of functioning effectively in neutral to acid side flotations.

Figures 8 and 9 show a recent data set generated by this author on an ore having gold associated with pyrite from South America. The $\mathrm{pH}$ in this data set is controlled by sulfuric acid addition on the acid side and lime on the alkaline side. All experiments were carried out in a 2-L batch-flotation cell using a blended frother of polypropylene glycol methyl ether components ranging in molecular weight from 200 to 400 . The frother dosage was held constant at $35 \mathrm{~g} / \mathrm{t}$, and the grind size was $78 \%$ less than $75 \mu \mathrm{m}$. The various collector dosages were adjusted to give approximately the same maximum gold recovery capable with each collector. The mercaptobenzothiazole (MBT) at $80 \mathrm{~g} / \mathrm{t}$, the ethyl isopropyl thionocarbamate at $40 \mathrm{~g} / \mathrm{t}$ and the mixture of MBT and di-isobutyl dithiophosphate at $80 \mathrm{~g} / \mathrm{t}$ were each added to the grind. The isobutyl xanthate at $120 \mathrm{~g} / \mathrm{t}$ and the mixture of isobutyl xanthate and the thio ether amine $\left(\mathrm{C}_{6} \mathrm{H}_{13} \mathrm{SCH}_{2} \mathrm{CH}_{2} \mathrm{NH}_{2}\right)$ at $80 \mathrm{~g} / \mathrm{t}$ were added to the cell.

Figures 8 and 9 show a number of trends that this author has found to be valid over the ten studies of various ores that had gold associated with pyrite. The first trend is that it is possible to develop a large number of reagent schemes (mostly collector blends) for such ores, regardless of the desired $\mathrm{pH}$ range of operation. On the alkaline side, a xanthate is probably the most effective major collector component to use. On the acid side, a mercaptobenzothiazole is probably the most effective major collector component to use.

The second trend, the observation that the maximum gold recovery in associated pyrite ores is always achieved by a blend of two or more collectors, has already been implied. The dithiophosphates, especially di-isobutyl dithiophosphate, are particularly good blending collectors for gold associated with iron sulfldes. With such ores, almost any collector blend is preferred over a single collector. More recently, some new and specialized collectors developed by a number of companies are being used for such blending. For example, on the acid side, monothiophosphate is showing promise, and, on the alkaline side, nitrogen-containing collectors in blends have given good results, e.g., Klimpel (1994). 


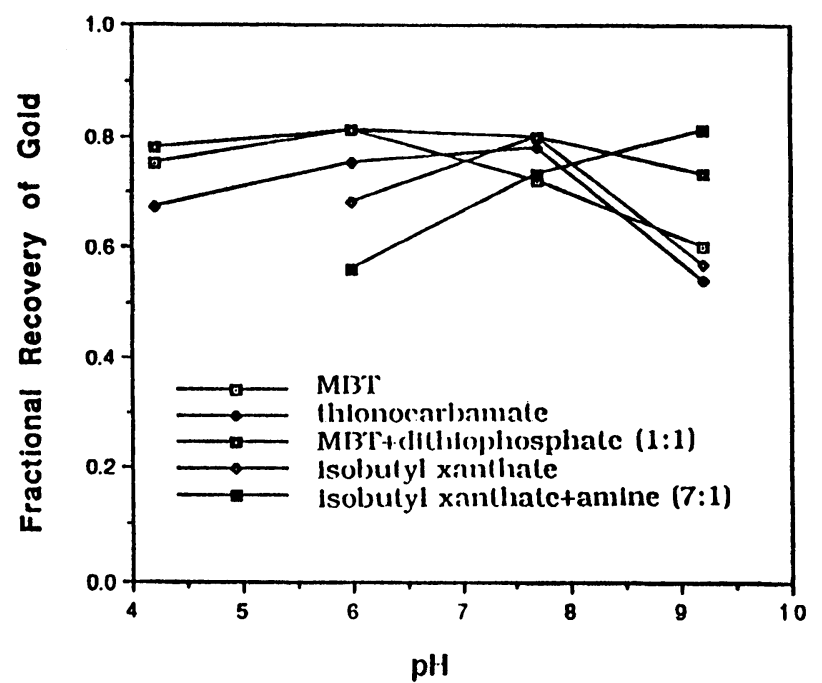

Figure 8 - The recovery of gold associated with pyrite using a blended PGME frother (molecular weight 200 to 400 ) at $35 \mathrm{~g} / \mathrm{t}$.

The third trend is that, to achieve high gold recovery in systems where gold is associated with pyrite, it is generally necessary to maximize the recovery of pyrite. For example, in Fig. 9, even a recovery of $+90 \%$ of the pyrite only achieves a $+80 \%$ recovery of the gold. In this author's plant experiences, the dropping off of the pyrite recovery of even a few percent can significantly impact the gold recovery. This situation almost always implies the use of high reagent dosages, the use of activators, the very specific control of $\mathrm{pH}$ and the use of lots of flotation capacity to handle the large tonnages of concentrate.

When the goal of a pyritic gold flotation is to produce sulfuric acid by roasting the concentrate, the need to maintain sufficient pyrite grade for self-roasting can result in significant gold losses. Achieving high gold recovery and high sulfur pyrite concentrate grade are usually incompatible goals and, like so many other flotation recovery-grade trade-offs, achieving an acceptable economic balance can be difficult. There really isn't a simple reagent solution to this balancing problem other than to treat each ore as a unique case and to avoid reagent overdosing, whatever the collector scheme chosen.

The recovery of gold associated with arsenopyrite and pyrrhotite has a similar response pattern from both collector and $\mathrm{pH}$ viewpoints, as illustrated in Figs. 8 and 9. It is sometimes desired to recover arsenopyrite away from pyrite. This is also an active area of flotation research and clearly, the regulation of flotation-pulp electrochemistry has a major bearing on the efficiency possible with this specific separation. The idea here is to find an electrochemical window where collector adsorption occurs on one mineral species, e.g., arsenopyrite, and not on another mineral species, e.g., pyrite.

Very preliminary work with chelation-oriented collectors also shows some promise in this type of separation. In this author's experience, arsenopyrite/pyrite systems have a tendency to be unique to a given ore body, so that what works with one ore does not always work well with other ores.

Copper sulfate is often used as an activator in the flotation of gold associated with iron sulfides. Experimentally, when copper sulfate is used in the flotation of gold-bearing pyritic ores, the recovery is higher and the rate of flotation is faster. The use of copper sulfate is particularly effective in improv-

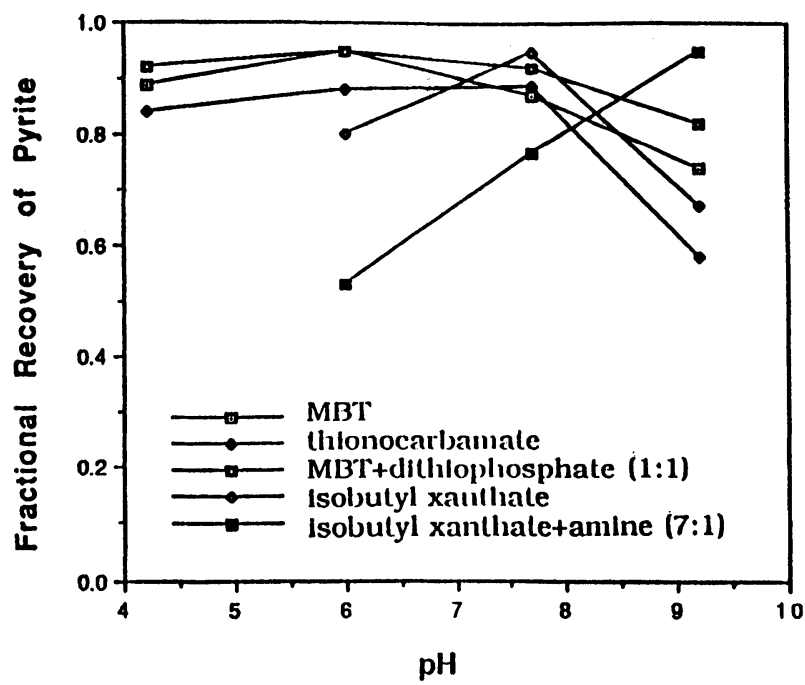

Figure 9 - The recovery of pyrite in an ore in which the gold is associated with the pyrite using a blended PGME frother (molecular weight 200 to 400 ) at $35 \mathrm{~g} / \mathrm{t}$.

ing relatively coarse particle flotations involving pyrite. The adsorption of copper sulfate onto pyrite is higher at neutral to acidic $\mathrm{pH}$ levels than it is in the alkaline region. With regard to dosage, too much copper sulfate causes froth instability.

Gold associated with $\mathrm{Cu} / \mathrm{Pb} / \mathrm{Zn}$ ores. The recovery of gold associated with complex base-metal sulfide ores is difficult to optimize from a reagent viewpoint. Typically, this type of complex mineralogy is treated by first removing the copper and lead (including silver) sulfides at a moderately alkaline $\mathrm{pH}$ of 8.5 to 9.5 . This is then followed by a second stage of copper sulfate activation of the zinc sulfides followed by flotation at a somewhat higher $\mathrm{pH}$ of 9.5 to 10.5 . The gold recovery associated with such a two-, or more, stage flotation process is often poor and can be less than $50 \%$. There are many reasons for this, including the general desire to selectively float copper and lead sulfides over iron sulfides and the shorter flotation times that are given to the initial flotation stages to minimize the level of zinc sulfides occurring in the $\mathrm{Cu} / \mathrm{Pb}$ concentrates. The zinc depressants sometimes used in the first-stage of $\mathrm{a} \mathrm{Cu} / \mathrm{Pb}$ flotation can also have a negative impact on gold recovery.

Generally, experience has shown that, the lower the $\mathrm{pH}$ of the $\mathrm{Cu} / \mathrm{Pb}$ first-stage flotation, the better the gold recovery in the first stage. It is generally desired to have the preciousmetal recovery occur early in the flotation process. Adding collectors such as dithiophosphates and phosphinates to a collector blend can help gold recovery in the $\mathrm{Cu} / \mathrm{Pb}$ recovery stage. In some ways, recovering gold in complex base metal flotations is similar to that of recovering gold associated with pyrite.

Better results are achieved with blended collectors, and there is a tendency to over reagentize such systems leading to the need for different depressants. There are, of course, many restrictions placed on complex metal sulfide flotations to guarantee satisfactory recoveries of $\mathrm{Cu}$ and $\mathrm{Zn}$ first and $\mathrm{Au}$ second, because gold generally is present in small amounts in such ores.

Mixed-ore mineralogy where there is some gold species tending to float with little collector. It is not unusual to have gold present in several different forms in any given ore. A typical example of a mixed ore is one having some level of 
free or native gold occurring with the remainder being associated with various types of sulfide minerals. Sometimes, the approach to such an ore is to treat the total ore as a gold associated pyritic ore leading to high levels of collectors being used. As an alternative, this author has had good success with several mixed ores using a simple two-stage rougher approach that can be evaluated in a testing program at the same time as the massive-sulfide high-reagent approach. The first stage consists of carrying out a natural or near natural $\mathrm{pH}$ float with only small amounts $(<10 \mathrm{~g} / \mathrm{t})$ of an uncharged water-insoluble collector. As has been amply presented in this article, such an approach is best for recovering that portion of the mineralogy that has natural or collectorless flotation tendencies. This is then followed by a second more highly reagentized flotation scheme.

There are several advantages of this two-stage approach for mixed gold ores. The first is that those minerals that have a natural tendency to float without collector can be removed cheaply and quickly. The rate of flotation of such minerals is usually higher than with highly reagentized minerals. Also, such inherently naturally floating materials are not very sensitive to water chemistry variations, even including the use of seawater (Klimpel, 1997b). Once the easy-to-float minerals are removed, the remaining gold-containing minerals can be recovered by higher dosages of charged watersoluble collectors.

With much of the gold already removed in the first stage, typically $30 \%$ to $70 \%$, the remaining gold associated mineralogy can be treated by higher dosages of reagents per ton of feed. However, in this author's various tests over the years, it has almost always been the case with this second-stage mineralogy that the dosage of the collectors, while much higher than the first-stage flotation, is measurably less per ton than if the first-stage removal of material had not been carried out. Possibly even more unexpected, the selectivity of the second stage and the rate of flotation are better with no $\mathrm{pH}$ adjustment than if the entire flotation feed were treated by a high-dosage reagent scheme operating at an optimally adjusted pulp pH. Another benefit of the two-stage flotation process for gold is that it allows for greater retention time to be allocated to the slower floating and more highly reagentized species.

To put it another way, it is always advantageous with mixed gold mineralogy having some natural flotation tendencies to remove the inherently naturally floating material immediately. The first-stage concentrate produced by such naturally floating materials is more selective, faster floating (requiring less cell capacity) and, from a reagent cost viewpoint, much cheaper than treating all of the feed ore with high reagent dosages.

As an example, in one ore-evaluation study conducted by this author, the two-stage approach showed that $55 \%$ of the total gold could be recovered with a 4-min rougher-cell retention time and with no $\mathrm{pH}$ adjustment. The reagent cost was $\$ 0.08 / \mathrm{t}$ of flotation feed. This was followed by a high reagent-dosage second-stage rougher requiring an additional 12 min of retention time to recover $35 \%$ of the total gold with no $\mathrm{pH}$ adjustment. The additional reagent cost was $\$ 0.19 / \mathrm{t}$ of flotation feed. Thus, using the two-stage rougher approach, the total residence time required was $16 \mathrm{~min}$, and the total rougher reagent cost was $\$ 0.27 / \mathrm{t}$ of flotation feed. The rougher concentrates from both stages were then combined and cleaned together.

This two-stage process for this ore was then compared to treating the entire flotation feed with the high reagent scheme to give the same $90 \%$ gold recovery goal. With the highreagent scheme applied to the total ore, the total required rougher retention time was $24 \mathrm{~min}$ and involved $\mathrm{pH}$ regulation costs of $\$ 0.12 / \mathrm{t}$ of feed and a total collector and frother reagent cost of $\$ 0.37 / t$ of feed ore. The economic advantage of the two-stage rougher approach is quite evident, both from a capital savings as well as lower reagent costs. Experience has also shown, that the first- and second-stage rougher concentrates can be combined for cleaning with little difficulty. In some cases, a small amount of lime addition to the cleaner has been necessary if no lime had been added to either of the two rougher stages.

Gold ores and slime influences. Another problem that is present in the flotation of many gold ores is the adverse impact of fine slime particles adhering to the valuable freegold particles and/or to the gold associated with other minerals. The slime particles can be fine silicas, silicates, clays, sulfldes, etc. There are three major impacts of slimes in gold flotation:

- the, sometimes, much higher reagent dosage required to achieve acceptable gold recoveries due to the excessive surface area present with slimes;

- with some ores, no matter what collector dosage is utilized, the gold recovery is unacceptably poor; and

- the presence of slimes can significantly slow down the rate of flotation of gold species.

It has consistently been this author's experience that small amounts of polymeric dispersants, e.g., 10 to $25 \mathrm{~g} / \mathrm{t}$, such as sodium polyacrylate can have a positive impact on gold recovery and gold kinetics. This has been true, even when a particular gold ore is considered to not have slime interference characteristics.

As an example of the impact of efficient dispersant use in gold flotation, the data of Fig. 10 shows the impact of adding a polyacrylate dispersant to a primarily free gold flotation using a dithiophosphate collector. There clearly is an impact of the dispersant on the equilibrium gold recovery but the greatest impact of the dispersant is the almost doubling of the rate of flotation. This example is another illustration of just how sensitive the flotation rate of gold is to adverse operating conditions.

Inorganic dispersants, especially sodium silicate, are cheaper per unit of mass, but, to have a positive effect with inorganics, the dosage can be anywhere from two to 20 times as high as with the polymer dispersants. Thus, the use of polymeric dispersants is often more cost effective. In addition, the use of higher levels of inorganic dispersants can cause undesired and sometimes complex mineral surfaceproperty changes that make control of gold flotation processes more difficult.

\section{Conclusions}

- The selection of an optimal flotation reagent scheme for gold flotation is very dependent on the specific mineralogy of the gold ore to be processed.

- Free or natural gold is optimally recovered using a reagent approach consistent with that successfully utilized in the recovery of copper sulfide minerals that have inherent natural or collectorless floatability. This implies natural or near-natural $\mathrm{pH}$ and the use of small amounts $(<10 \mathrm{~g} / \mathrm{t})$ of an uncharged water insoluble collector. 

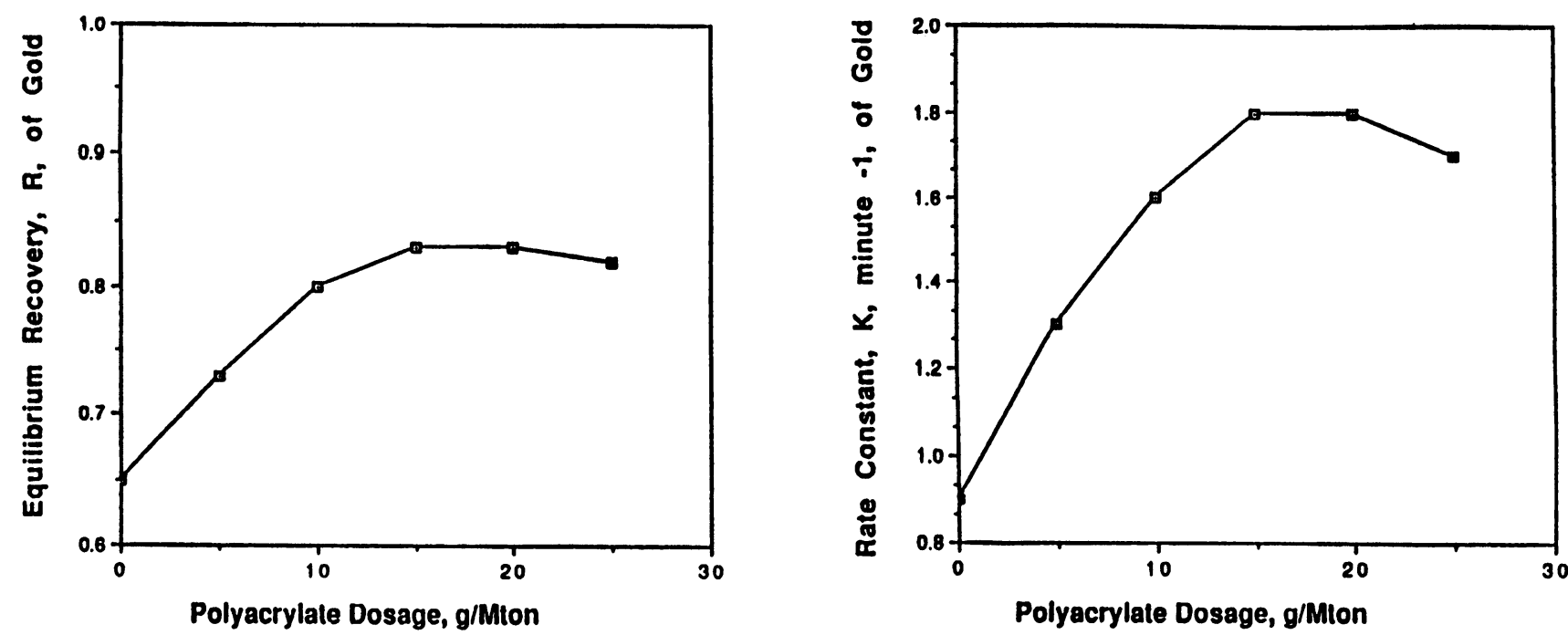

Figure 10 - The trends in $\mathrm{R}$ and $\mathrm{K}$ parameters resulting from curve fitting experimental time-recovery profiles of an ore having slime interference as a function of sodium polyacrylate addition, molecular weight 10,000 . The collector is di-isobutyl dithiophosphate at $60 \mathrm{~g} / \mathrm{t}$, the $\mathrm{pH}$ is 7.8 , and the frother is a PGME ( 250 molecular weight) at $17 \mathrm{~g} / \mathrm{t}$. The grind size is $68 \%$ $<75 \mu \mathrm{m}$.

- Inherently naturally floating minerals float fast kinetically; are relatively selective against other sulfides, including pyrite; are relatively insensitive to water chemistry variations, allowing for even seawater to be used effectively; and are effectively recovered at natural ore $\mathrm{pH}$ levels.

- Gold associated with iron sulfides can be recovered optimally in either acidic or alkaline conditions, usually with larger amounts (>50 g/t) of charged water soluble collectors. Effective collectors are available for either $\mathrm{pH}$ regime. Xanthates are the primary major collector component on the alkaline side and mercaptobenzothiazole is the major collector component on the acidic side. Blends of different collectors are particularly effective with gold associated with iron sulfides or with base metal sulfide ores. The dithiophosphates are, in any given application, an effective additional component to a collector blend to enhance gold recovery.

- Gold flotation is inherently a slow kinetic process. Thus, any operating and/or reagent condition that slows down the rate should be avoided. Typical adverse conditions are excessive dosages of collectors, high slime presence, low pulp densities and cold processwater conditions. There is nothing more golden in gold flotation than having lots of retention time.

- The choice of a particle size balanced frother having a high flotation rate is important in gold flotation, with generally glycol or polypropylene glycol methyl ether frothers being preferred over alcohol frothers.

- Larger free-gold particles float slower than finer particles and also require more collector to recover by flotation. Thus, care has to be taken to avoid over-reagentizing the fines and, thus, losing fine-particle recovery in an attempt to increase the coarse particle recovery, i.e., to avoid the $\mathrm{R} / \mathrm{K}$ trade-off that can occur with all minerals in flotation.

- Whenever possible, to reduce reagent and capital costs and to get the highest possible gold recoveries with mixed mineralogy gold ores having some minerals that float naturally, a two-stage rougher-flotation scheme is recommended. In the first stage, the inherently naturally floating minerals are removed first at natural $\mathrm{pH}$ with small $(<10-\mathrm{g} / \mathrm{t})$ dosages of an uncharged waterinsoluble collector. Then, the remaining gold species are recovered in a second stage using higher collector dosages and also collector blends, again at or near natural $\mathrm{pH}$. The two-stage rougher concentrates can be cleaned together sometimes requiring the use of a small amount of lime.

\section{References}

Aplan, F.A., and Chander, S., 1988, "Collectors for sulfide mineral flotation," Reagents in Mineral Technology, P. Somasundaran and B.M. Moudgil, eds., Marcel Dekker, New York, pp. 335-370.

Crozier, R.D., 1992, Flotation, Pergamon Press, New York.

Dowling, E.C., Klimpel, R.R., and Aplan, F.A., 1985, "Model discrimination in the flotation of a porphyry copper ore," Minerals \& Metallurgical Processing, Vol. 2, No. 2, pp. 87-101.

Fuerstenau, D.W., 1989, "Flotation Reagents," Advances in Coal and Mineral Processing Using Flotation, S. Chander and R.R. Klimpel, eds., Society of Mining, Metallurgy, and Exploration, Littleton, CO, pp. 3-18.

Fuerstenau, M.C., and Hendrix, J.L., eds., 1990, Advances in Gold and Silver Processing, Society of Mining, Metallurgy, and Exploration, Littleton, $\mathrm{CO}$.

Fuerstenau, M.C., Miller, J.D., and Kuhn, M.C., 1985, Chemistry of Flotation, Society of Mining Engineers of AIME, New York.

Harris, G.H., 1988, "Xanthates," Reagents in Mineral Technology, P. Somasundaran and B. M. Moudgil, eds., Marcel Dekker, New York, pp. 39-78,

Hausen, D.M., Halbe, D.N., Peterson, E.U., and Taturi, W.J., eds., 1990, Gold-90, Society of Mining, Metallurgy, and Exploration, Littleton, CO.

Klimpel, R.R., and Isherwood, S., 1991, "Some industrial implications of changing frother chemical structure," Int. J. of Mineral Processing, Vol. 33, pp. 369-381.

Klimpel, R.R., 1980, "Selection of Chemical Reagents in Froth Flotation," Mineral Processing Plant Design, 2nd Ed., A. Mular and R. Bhappu, eds., Society of Mining Engineers of AIME, New York, pp. 907-934.

Klimpel, R.R., 1989, "The industrial mineral flotation system", $A d-$ 
vances in Coal and Mineral Processing Using Flotation, S. Chander and R.R. Klimpel, eds., Society of Mining, Metallurgy, and Exploration, Littleton, CO, pp. 273-286.

Klimpel, R.R., 1994, "A discussion of traditional and new reagent chemistries for the flotation of sulfide minerals," Reagents for Better Metallurgy, P.S. Mulukutla, ed., Society of Mining, Metallurgy, and Exploration, Littleton, Colo., pp. 59-66.

Klimpel, R.R., 1995, "Gaudin award lecture - Technology trends in froth flotation chemistry," Mining Engineering, Vol. 47, No. 10, pp. 933-942.

Klimpel, R.R., 1997a, "Flotation kinetic studies - Going from laboratory to the plant," Proceedings of the 29th Annual Meeting of Canadian Mineral Processors, Canadian Institute of Mining, Ottawa, Ontario, Canada, pp. 357-366.

Klimpel, R.R., 1997b, "The effect of water chemistry, reagent type, and other environmental factors on the performance of industrial grinding and flotation processes involving sulfide minerals," $X X$ International Mineral Processing Congress Proceedings, Aachen, Germany.

Klimpel, R.R., and Isherwood, S., 1993, "Some new flotation products for improved recovery of gold and platinum," Randol Gold
Forum - Beaver Creek, CO, Randol Publishing, Golden, CO, pp. 105-112.

Malhotra, D., ed., 1993, Flotation Plants: Are they Optimized? Society of Mining, Metallurgy, and Exploration, Littleton, CO.

McQuiston, F.W., and Shoemaker, R.S., 1985, "Precious metals," SME Mineral Processing Handbook, Section 18, N. L. Weiss, ed., Society of Mining Engineers of AIME, New York, pp. 18-1 to 18-36.

O'Connor, C.T., and Dunne, R.C., 1994, "The flotation of gold bearing ores - A review," Minerals Engineering, Vol. 7, No. 7, pp. 839-849.

Riggs, W.F., 1986, "Frothers - An operator's guide," Chemical Reagents in the Mineral Processing Industry, D. Malhotra and W.F. Riggs, eds., Society of Mining Engineers of AIME, Littleton, CO, pp. 113-116

vanZyl, D.J., Hutchison, I.P., and Keil, J.E., eds., 1988, Introduction to Evaluation, Design, and Operation of Precious Metal Heap Leaching Projects, SME/AIME, Littleton, CO.

Woods, R. 1988, "Flotation of sulfide minerals," Reagents in Mineral Technology, P. Somasundaran and B. M. Moudgil, eds., Marcel Dekker, New York, pp. 39-78. 